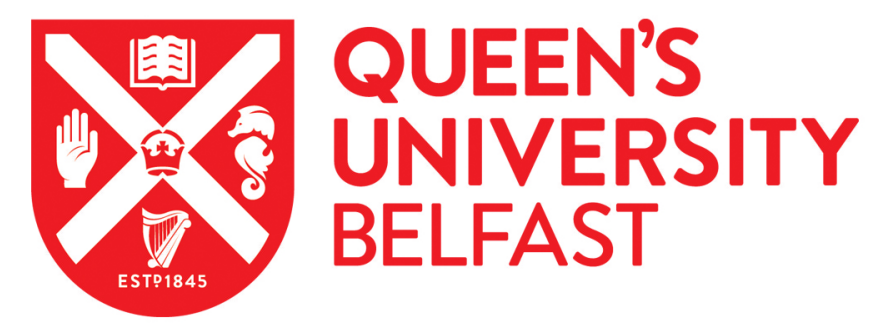

\title{
A randomized controlled efficacy trial of a smoking prevention programme with Grade 8 students in high schools
}

Thurston, A., Dunne, L., Kee, F., Gildea, A., Craig, N., Stark, P., \& Lazenbatt, A. (2019). A randomized controlled efficacy trial of a smoking prevention programme with Grade 8 students in high schools. International Journal of Educational Research, 93, 23-32. https://doi.org/10.1016/j.ijer.2018.10.003, https://doi.org/10.1016/j.ijer.2018.10.003

Published in:

International Journal of Educational Research

Document Version:

Peer reviewed version

Queen's University Belfast - Research Portal:

Link to publication record in Queen's University Belfast Research Portal

Publisher rights

Copyright 2018 Elsevier

This manuscript is distributed under a Creative Commons Attribution-NonCommercial-NoDerivs License

(https://creativecommons.org/licenses/by-nc-nd/4.0/), which permits distribution and reproduction for non-commercial purposes, provided the author and source are cited.

\section{General rights}

Copyright for the publications made accessible via the Queen's University Belfast Research Portal is retained by the author(s) and / or other copyright owners and it is a condition of accessing these publications that users recognise and abide by the legal requirements associated with these rights.

Take down policy

The Research Portal is Queen's institutional repository that provides access to Queen's research output. Every effort has been made to ensure that content in the Research Portal does not infringe any person's rights, or applicable UK laws. If you discover content in the Research Portal that you believe breaches copyright or violates any law, please contact openaccess@qub.ac.uk. 
Title page

A randomized controlled efficacy trial of a smoking prevention programme with Grade 8 students in high schools

\author{
Authorship: Allen Thurston, Laura Dunne, Frank Kee, Aidean Gildea, Nicole \\ Craig, Patrick Stark, Anne Lazenbatt (all Queen's University Belfast)
}

Corresponding author: Allen Thurston, Cell: +447964916186, email: a.thurston@qub.ac.uk

Address: Centre for Evidence \& Social Innovation, Queen's University Belfast, 20 College Green, Belfast, BT71LN, United Kingdom.

\title{
Acknowledgements and Statements of Funding
}

The work was funded through an open competition grant from Public Health Agency (PHA). The work was managed through the PHA, but part of the funding came from Cancer Focus NI. Queen's University Belfast evaluated Dead Cool independently from Cancer Focus NI, who played no part in identifying the main outcome measures, data collection or data analysis. We would especially like to thank the young people and school personnel who participated in the study, without their time and commitment this research would not have been possible.

\begin{abstract}
The study undertook a Level 3 efficacy trial of a smoking prevention programme in Grade 8 high-school classrooms. A smoking prevention programme, 'Dead Cool', was tested in a randomized controlled trial. 17 Grade 8 classes were randomly assigned to intervention or control arms of the trial. The intervention was a cooperative learning-based intervention of five, 40 minute lessons delivered by teachers, but designed by Cancer Focus NI. The primary outcome was smoking as measured by carbon monoxide (CO) in exhaled breath. Measurements of $\mathrm{CO}$ were undertaken pre-test, immediately post-test and three months after the intervention. Multi-level modelling indicated the programme prevented smoking initiation in Grade 8 students. Implications for research and design of school-based smoking prevention programmes are discussed.
\end{abstract}

\section{Significant contribution}

This research reports on a smoking prevention Level 3 efficacy trial with Grade 8 high-school students. The intervention relied on developing resilience to peer and advertiser pressure. The programme prevented smoking commencement in 
intervention schools. Smoking was measured using exhaled breath carbon monoxide and did not rely on self-reported measures.

\section{Introduction}

Research suggests that $7 \%$ of children aged 11-16 in Northern Ireland were smoking in 2010 (Department of Health, Social Services and Public Safety Northern Ireland, 2012). In 2013, 19\% of adults in Great Britain were smokers (Health and Social Care Information Centre, 2015). It is estimated that around $40 \%$ of regular smokers in Great Britain began smoking before age 16 (Office for National Statistics, 2013). Half of all smokers will die prematurely as a result of their smoking (World Health Organisation, 2006). Evidence shows that teenagers become quickly addicted to tobacco (DiFranza, Savageau, Fletcher, O'Loughlin, Pbert, Ockene \& Wellman, 2007) and that those who begin to smoke earlier are more likely to be regular smokers in adulthood (Chassin, Presson, Sherman \& Edwards, 2000; Taioli \& Wynder, 1991). There is therefore a need to develop effective smoking prevention education in schools. This paper reports on a Level 3 efficacy trial (Early Intervention Foundation, 2018) of one such education programme.

Between 1998 and 2009 smoking rates in the UK reduced by $23 \%$. This reduction can be attributed to tobacco control policies, such as tax increases, smoke-free air laws, the restriction of tobacco advertising and the increased availability of tobacco cessation services (Levy, Currie and Clancy, 2013. However, the gap in smoking rates between those in high and lower socioeconomic groups has widened over the same period (Cancer Research UK, 2014). It is crucial that policy is informed by evidence. There is still some debate around the optimal time to intervene to prevent smoking initiation in young people. As initiation begins to increase around the ages of 11-12 years, this is potentially a good time to intervene (Fuller, 2014).

Peers have previously been reported to be instrumental in initiating smoking behaviours in school-aged students. Student attitudes and behaviours surrounding smoking have been noted to be mediated by personal knowledge and how peers behave (Campbell, Starkey, Holliday, Audrey, Bloor, Parry-Langdon \& Moore, 2008). These conclusions are backed up by a recent systematic review that concluded that school based smoking prevention interventions that considered social competence and or social influence components were effective (Thomas, McLellan \& Perera, 2013; Thomas, McLellan \& Perera, 2015). Therefore, it is vital to use pedagogies that address peer interactions and metacognitive aspects of learning (to help students make informed decision about why they would, or would not, choose to smoke). Cooperative learning is noted to facilitate such metacognitive learning (Campione, Shapiro \& Brown, 1995) and has been shown to influence patterns of peer interaction and friendship (Tolmie, Topping, Christie, Donaldson, Howe, Jessiman, Livingston \& 
Thurston, 2010). Therefore, it is important that smoking prevention programmes use effective pedagogies to help students learn about cigarette use. Cooperative learning provides an excellent technique within which to situate smoking prevention programmes. The opportunities for peer to peer discussion and debate allow ideas to be explored and debated.

\section{The aim of the current study}

The aim of this study was to use a pragmatic randomized controlled trial design to assess the efficacy of the Dead Cool programme on smoking related outcomes in Grade 8 young. In addition, we wanted to examine the programme and make judgements regarding any adaptations and developments that might be required if attempts were to be made to scale Dead Cool for more extensive implementation and roll-out. A qualitative process evaluation was therefore conducted alongside the trial. Overall, this work aims to contribute to knowledge around the prevention of smoking initiation in Grade 8 young people. In terms of this aim it was also planned to establish the actual delivery 'dose' that implementation classrooms achieved.

\section{The intervention}

Dead Cool is a smoking prevention programme for Grade 8 students designed by Cancer Focus NI. It is a manualised programme with set a set series of lessons, plus extension sessions for teachers (Cancer Focus NI, 2015). Grade 8 students in Northern Ireland are normally in the range 13-14 years old. They are attending high school by this stage. Post-primary school is used in Northern Ireland to refer to the disparate 'high' school system and includes secondary/high, grammar, 'comprehensive', religious affiliated, state run and independent schools that may be single sex or co-educational. Dead Cool is delivered by teachers and comprises four lesson plans (that can be delivered over five sessions if required) and an accompanying resource pack. The programme aims to reduce the number of young people who start smoking and encourage them to challenge those who influence smoking behaviour such as friends, parents, other family members, and explore the influence of direct and indirect cigarette placement in the media. Teachers from the school deliver the programme in their own classes over a four-week period. The lessons last for approximately 40 minutes. There is an accompanying DVD of short video clips that supplement each lesson which feature teenagers from Northern Ireland. Prior to the programme the students have an introductory session delivered by a Cancer Focus NI employee. The total time that the students are engaged by the programme varies between three to four hours during a period of up to six weeks. In addition to the 'pack' teachers receive 90 minutes of professional development where the focus and epistemology behind the product design is outlined. A fuller description of each lesson follows in the methodology. The lessons engage the students in cooperative learning. The lessons create learning contexts where social 
interdependence is required for success (Johnson, Johnson \& Roseth, 2010; Johnson \& Johnson 2012), including:

- Goal structure (the groups work together with the aim of completing a group booklet about social and media issues surrounding smoking)

- Positive interdependence (in the cooperative learning processes clear tasks are assigned within each group whereby group members take responsibility)

- Individual accountability (all group members must contribute and express opinions to allow the booklet to be completed)

- Interaction patterns (the cooperative learning processes were structured to stimulate promotive interaction, group processing and to enhance social skills)

\section{Methods}

\section{Introduction}

A randomized controlled trial was undertaken to explore the impact of the programme on smoking related outcomes. Guided by the recent MRC guidance, alongside this a qualitative process evaluation was conducted which aimed to explore the validity of the logic model and the pathways through which the programme might work (Moore, Audrey, Barker, Bond, Bonnell, Hardeman, Moore, O'Cathain, Tinati, Wight \& Baird, 2017). Note that data from the process evaluation is presented briefly here, but will be reported in full elsewhere. A full description of the protocol for this research was published and it was registered on the ISRCTN registry. (Dunne, Thurston, Kee, Lazenbatt \& Gildea, 2016; Thurston, Dunne, Kee, Gildea, Craig \& Stark, 2017).

\section{Research questions}

To determine the research question and primary outcome measure a Logic Model was designed with input from Cancer Focus NI staff. It is presented in Figure I. The project aimed to evaluate:

a) How effective is the Dead Cool programme at preventing the initialisation of smoking behaviours, as measured by carbon monoxide in exhaled breath, in Grade 8 students?

b) Can the programme be delivered with implementation integrity in the sample, and do levels of actual implementation indicate the programme could scale to an effectiveness full trial?

In this respect, the primary outcome from the study was exhaled breath carbon monoxide (CO) measures in Grade 8 students in Northern Ireland.

\section{Sample}

62 schools were invited to take part in the study. A total of 21 schools expressed an interest in receiving further information. Of these 18 schools committed to taking part 
after further discussion with the research team. 21 classes were randomized to the intervention. After randomisation, but before treatment, it was announced that one of the schools was to be closed as a result of budget cuts and it dropped out of the study, leaving 17 schools and 20 classes in the sample. Table 1 shows free school meal and school size data for the samples. Adaptive randomisation was used on the basis of school type and free school meal percentage. No significant differences were found between the intervention (26.36\%) and treatment as usual $(30.56 \%)$ on the basis of the proportion of pupils eligible for free school meals $(F(1,19)=0.54, P=0.47)$ or school size as intervention was (881.55 students) and treatment as usual was (922.7 students) $(F(1,19)=0.06, P=0.80)$.

Table 1: Percentage of free school meal and total number of students in the school data for the treatment as usual and intervention classes

\begin{tabular}{|l|l|l|}
\hline & Free school meal \% (SD) & $\begin{array}{l}\text { Total number of students } \\
\text { in school (SD) }\end{array}$ \\
\hline $\begin{array}{l}\text { Intervention classes } \\
\mathrm{N}=10\end{array}$ & $26.36(10.54)$ & $881.55(402.10)$ \\
\hline $\begin{array}{l}\text { Treatment as usual } \\
\text { classes N=10 }\end{array}$ & $30.56(15.40)$ & $922.7(338.59)$ \\
\hline
\end{tabular}

\section{Randomisation}

Northern Ireland has a diverse high school sector. With a total sample of 20 classes being randomized, it was deemed necessary (to mitigate the risk of skewness) to randomise the sample using both 'blocking' and 'minimisation', in order to minimize the risk of Type 1 error. In particular, adaptive randomisation was used on the basis of school type and free school meal percentage, with additional checks being made on final intervention and treatment-as-usual groups to ensure parity in school size and free school meal percentage. High schools were recruited including secondary (nonselective high schools)/grammar (selective high school intake based on academic attainment)/integrated (with a mixed intake of non-selective and selective students)/single sex/coeducational, rural and urban schools from both the Catholic Maintained and Controlled state sector and independent/voluntary (opted out of local authority control) sector schools. Recruitment took place by sending an email to all high schools within a radius of 30 miles from Belfast. This meant emails were sent to 66 schools. 22 expressed interest and 18 consented to taking part in the study. One school was closed by the Government prior to the trial taking place, leaving 17 schools. Northern Ireland has a complex high school composition. This includes grammar and secondary sectors which are split between those associated mainly with the Catholic and Protestant faiths. In addition, there are integrated schools enrolling pupils from both Catholic and Protestant populations and independent schools (which may or may 
not have a religious affiliation). Schools may have co-educational or single sex intake. Obviously, this disparate mix of school types needed to be balanced between intervention and treatment-as-usual groups to ensure parity between grammar/secondary school status (a proxy for student attainment at the end of Year 7), gender, ethnic background and socio-economic status. During recruitment to this sample, the evaluation team paired schools of a similar nature together. So, for example, two girls only, maintained, grammar schools were paired, two coeducational, controlled secondary schools were paired and so on. Then randomisation took place using adaptive minimisation at the pair level to ensure that there was balance in the type of school in the intervention and treatment-as-usual samples. Schools were rank ordered on the basis of free school meal percentage (a proxy for socio-economic deprivation) and schools were block randomized to condition. When the first school was randomized in a block then schools were sequentially assigned to condition to ensure that even numbers of samples were present in each condition. Classes from the same school were dealt with by including them on the list for randomisation as discrete classes. However, they were 'vertically' next to each other as they shared identical school level characteristics that were being used for minimisation. Note that in a small sample of 20 classes it was possible to have ended up with uneven intervention and treatment as usual group numbers if randomisation had taken place without blocking.

\section{Intervention}

Dead Cool starts with a visit from a member of the Cancer Focus NI team. They set the context for the project and provide an overview of the course that follows. This includes a video shot with local young people that will focus on the main topics that Dead Cool covers. Following the initial lesson/visit, the Dead Cool lesson sequence was as follows:

1. Lesson focussed on friends and levels of smoking in Northern Ireland-Students worked in pairs to discuss their personal experiences on smoking in response to a series of teacher posed questions as a 'think-pair-share' activity. Students then work in groups to undertake role-play activities surrounding being offered cigarettes. A video clip models role play activities and responses.

2. Lesson focussed on smoking within the family-Students work in rapid changing pairs to discuss topics such as smoke free environments, followed by a random reporter activity. Then students work in triads with allocated roles as parent, child and observer/reporter to role play surrounding conversations about smoking with parents. Reporters feed into discussion at the end. A video clip acts as a stimulus for this activity and provides commentary from students who have had similar conversations with parents.

3. The tobacco industry and subliminal advertising-This lesson starts with a video clip looking at subliminal advertising by celebrities and smoking, and looking at mortality rates from smoking behaviours. Students then work in groups and undertake internet research to find examples of smoking in movies, TV 
programmes, music video and paparazzi shot photographs of celebrities smoking. Students appoint a reporter and report back to the whole class on what their groups have found.

4. Review of learning-The final lesson focuses on reviewing what students have learned. Students work in groups to review 'Fact Files' and review their own learning and skills development. They identify topic for further research.

It should be noted that the pack included specific lesson plans, and group work sheets. Each lesson plan indicated activities and lessons and comprised an easy to follow guide for teachers. Students were provided with the photocopiable worksheets in pairs or in a group. In Northern Ireland smoking in a topic that must be covered as a statutory subject under the Education Authority curriculum on learning for life and work under the personal health key concepts topics as 'Investigate the effects on the body of legal and illegal substances and the risks and consequences of their misuse, for example, effects on behaviour, physical and mental health, life and work changes etc.' (Education Authority, 2018).

Dead Cool programme fidelity is supported by mentoring from Cancer Focus NI staff. Teachers undergo a half day training that is delivered by a member of staff from Cancer Focus NI prior to commencing implementing the programme. The trainer then provides ongoing mentoring support by being available via telephone or email if the teacher has any queries for the duration of programme implementation.

\section{Instruments}

Exhaled Carbon Monoxide (CO) level: The PICOSimple Smokelyser was chosen as a reliable instrument for measuring exhaled air $\mathrm{CO}$. Exhaled $\mathrm{CO}$ is a proxy for measurement of CO Haemoglobin levels (Kendrick, 2015). It was operated in accordance with the manual for operation and within time/use parameters for recommended recalibration (Bedfont, 2015). Use of $\mathrm{CO}$ in exhaled breath is a well established method of measuring smoking behaviour (e.g. Deveci, Deveci, Acik \& Ozan, 2004).

Data collection: Data collection was carried out between November and June in one school academic year. Both experimental and treatment as usual groups were tested at three points:

Time 0 (baseline t0): children were tested before the programme was implemented.

Time 1 (post-test $\mathrm{t} 1$ ): children were tested directly after the programme ended.

Time 2 (post-test t2): children were tested approximately 3.5 months after the programme had ended. 
Statistical methods: Descriptive statistics (means medians and contingency tables) were generated for each variable after appropriate distribution checks. The core demographic characteristics of the intervention and treatment as usual groups were compared and differences between groups across pre-test scores were evaluated. Due to the scaled nature of the exhaled $\mathrm{CO}$ measure this variable was analysed using multi-level modelling to establish patterns of changes within clusters (in this instance the classroom in which the intervention was delivered). Analysis was undertaken on an 'intention to treat' basis.

The selected sample size should be large enough to detect an Effect Size of +0.25 at $80 \%$ power and alpha $=0.05$ if analysed by ANCOVA and Hierarchical Linear Modelling. The sample was large enough to detect Effect Sizes of 0.4 with an ICC of 0.05 and 20 classes of at least 20 students in each, (to analyse $\mathrm{CO}$ in exhaled breath.)

\section{Process Evaluation}

A process evaluation was conducted alongside the randomized controlled trial in order to provide data on programme implementation and to capture the perceptions and experiences of key stakeholders' engagement with the programme. The purpose of the qualitative element of the evaluation was designed to provide a commentary on the process of the evaluation. Key areas explored were the quality of implementation of the intervention, fidelity and perceived programme outcomes. Four teachers in participating schools agreed to be interviewed and three focus groups were conducted with 6-10 students in each.

\section{Ethics}

The study was approved by the School of Social Sciences, Education \& Social Work, Queen's University Belfast Ethics Board. Information sheets were provided to all participants and opt out consent from students, teachers and senior management teams in schools was required to participate in the study. It should be noted that treatment as usual meant that schools continued with their planned, legally required, smoking prevention programmes. It was not considered morally or ethically acceptable to halt current practice to create a true 'control' that received no smoking prevention programme, nor that received a placebo of an ineffective programme.

\section{Results}

\section{Sample Characteristics}

Data was collected from 480 students. Mean age of the treatment as usual group was 12.51 (SD 0.51) years and of the intervention group it was 12.50 (SD 0.51) years. Age distribution did not differ significantly across groups $(F(1,478)=0.06, p=0.81)$. The sample was composed of 229 female/250 male students (1 student did not identify their gender). The ethnicity was 305 white Irish, 135 white British, 21 Asian, 5 African, 
4 Chinese and 5 who identified as "other". Pre and post-test data were collected for 399 students. The decision was taken to use $9 \mathrm{ppm}$ as the entry level exhaled breath $\mathrm{CO}$ to indicate smoking behaviours. This was based on previous reports that indicated that exhaled breath greater than 9ppm was indicative of smoking and that levels were not significantly different in children and adults. Exhaled $\mathrm{CO}$ levels have a half life of about 5 hours. In addition level of $\mathrm{CO}$ at $9 \mathrm{ppm}$ would not be presented due to 'passive smoking', which would remain lower than 8ppm (Deveci et al., 2004; Kendrick, 2015). Students with a Carbon Monoxide reading greater than 9ppm at pre-test t0 are excluded from data analysis. These would already be classified as smokers and therefore, would not be targeted by this smoking prevention intervention. Analyses were undertaken on students who had a pre-test Carbon Monoxide level of less than or equal to $9 \mathrm{ppm}$. This was because the programme was a smoking prevention, rather than cessation programme and these students with $\mathrm{CO}$ in exhaled breath greater than $9 \mathrm{ppm}$ were already being classified as smokers. This excluded 7 students from the study. 76 students were missing either at the pre or post testing session due to school absence on the day of testing and are excluded from analysis. A participant flow diagram is presented in Figure 2. At post-test (t1) the sample characteristics were 153 female, 180 male, 1 undeclared with an ethnicity composition of 230 white Irish, 80 white British, 14 Asian, 2 African, 3 Chinese and 3 who identified as "other". At posttest (t2) the sample characteristics were 129 female, 101 male, 1 undeclared with an ethnicity composition of 160 white Irish, 49 white British, 11 Asian, 4 African, 2 Chinese and 3 who identified as "other". 
Figure 2: Participant flow diagram

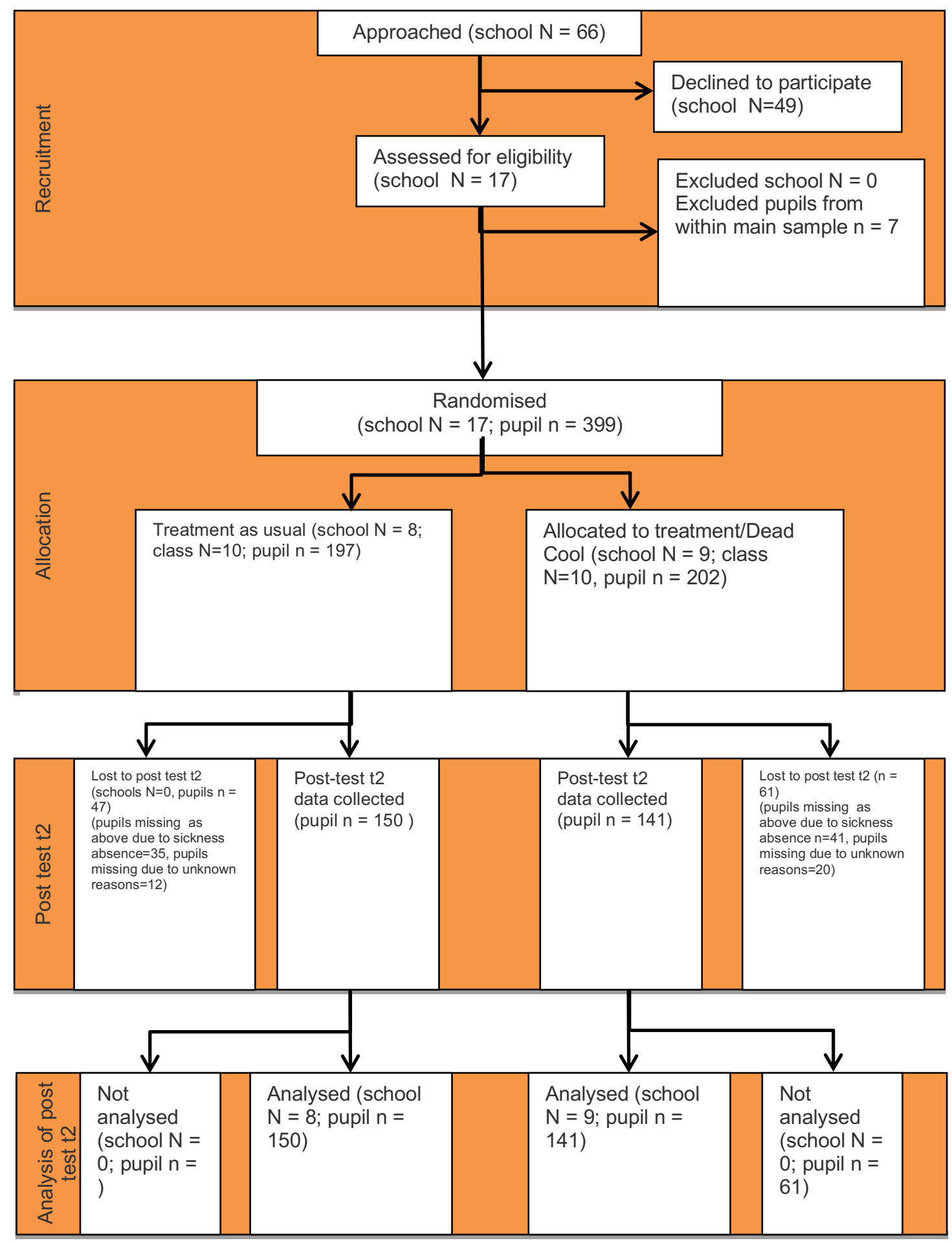




\section{Carbon Monoxide in exhaled breath}

Descriptive statistics of mean pre (t0), post test (t1) and post test (t2) CO in exhaled breath readings in parts per million ( $\mathrm{ppm}$ ) for treatment as usual and intervention samples are presented in Table 2. ANOVA indicated that there were no significant differences at pre-test $(t 0)(F(1,401)=2.08, p=0.15)$. However, given that there was difference in mean scores, then it was decided to control for pre-test difference in the HLM models developed. Data indicated that exhaled CO measurements were lower at both post test time points (correcting for pre test differences) in the intervention group with a Cohen's $d$ Effect Size of -0.17 at post test $\mathrm{t} 1$ and -0.38 at post test $\mathrm{t} 2$. This indicated lower levels of smoking initiation behaviours in the treatment group. 
Table 2: Mean pre (t0), post test $\mathrm{t} 1$ and post test $\mathrm{t} 2$ levels of Carbon Monoxide in exhaled breath reading of students in parts per million $(\mathrm{ppm})$ for treatment as usual and intervention groups

\begin{tabular}{|l|l|l|l|l|l|}
\hline Group & $\begin{array}{l}\text { Mean pre } \\
\text { test CO } \\
\text { exhaled } \\
\text { breath } \\
\text { ppm (SD) }\end{array}$ & $\begin{array}{l}\text { Mean post } \\
\text { test t1 CO } \\
\text { exhaled } \\
\text { breath ppm } \\
\text { (SD) }\end{array}$ & $\begin{array}{l}\text { Mean } \\
\text { change in } \\
\text { exhaled } \\
\text { breath at } \\
\text { t1 ppm }\end{array}$ & $\begin{array}{l}\text { Mean post } \\
\text { test t2 CO } \\
\text { exhaled } \\
\text { breath ppm } \\
\text { (SD) }\end{array}$ & $\begin{array}{l}\text { Mean } \\
\text { change in } \\
\text { exhaled } \\
\text { breath at } \\
\text { t2 ppm }\end{array}$ \\
\hline $\begin{array}{l}\text { Treatment } \\
\text { as usual }\end{array}$ & $\begin{array}{l}2.09(1.35) \\
\mathrm{n}=197\end{array}$ & $\begin{array}{l}1.81(1.02) \\
\mathrm{n}=154\end{array}$ & -0.28 & $\begin{array}{l}1.56(2.19) \\
\mathrm{n}=141\end{array}$ & -0.53 \\
\hline Intervention & $\begin{array}{l}2.48(1.82) \\
\mathrm{n}=202\end{array}$ & $\begin{array}{l}1.90(1.47) \\
\mathrm{n}=175\end{array}$ & -0.58 & $\begin{array}{l}1.27(1.24) \\
\mathrm{n}=150\end{array}$ & -1.21 \\
\hline $\begin{array}{l}\text { Total } \\
\text { combined } \\
\text { sample }\end{array}$ & $\begin{array}{l}2.29(1.61) \\
\mathrm{n}=399\end{array}$ & $\begin{array}{l}1.85(1.28) \\
\mathrm{n}=329\end{array}$ & & $\begin{array}{l}1.41(1.77) \\
\mathrm{n}=291\end{array}$ & \\
\hline
\end{tabular}

A two-level model was used to analyse data as the intervention was delivered at the class level, and there was very low risk of contamination in the three schools that ran both treatment as usual, and intervention programmes in classes. The risk was low as training and resources packs were restricted to intervention classes and we had a memorandum of understanding with the school that they would not use the intervention in treatment as usual classes. HLM analysis was performed on the sample using the following models and analysis is presented in Table 3 . Therefore, two models were developed to measure differences at post test $\mathrm{t} 1$ and post test $\mathrm{t} 2$, adjusting for pre-test score t0:

Post-test $t t 1_{i j}=\beta_{0 i j}+\beta_{1}\left(\right.$ pre-test score $\left.t O_{i j}\right)+\beta_{2}\left(\right.$ intervention group $\left.p_{i j}\right)$

Post-test $t 2_{i j}=\beta_{0 i j}+\beta_{1}\left(\right.$ pre-test score $\left.t 0_{i j}\right)+\beta_{2}$ (intervention group $\left.p_{i j}\right)$ 
Table 3: Multi level model analysis on collected data set, and with multiple imputation to deal with missing data, of levels of Carbon Monoxide in exhaled breath levels in students (ppm) at post test $\mathrm{t} 1$ and post test $\mathrm{t} 2$

\begin{tabular}{|c|c|c|c|c|c|c|}
\hline \multicolumn{7}{|c|}{ Model of exhaled breath CO levels in students (ppm) at post-test t1 } \\
\hline Model & $\mathrm{n}(\mathrm{N})$ & $\beta$ & SE & $95 \% \mathrm{Cl}$ & $\begin{array}{l}P \\
\text { value }\end{array}$ & $\begin{array}{l}\text { Effect Size } \\
\text { (intervention } \\
\text { compared to } \\
\text { treatment as } \\
\text { usual) }\end{array}$ \\
\hline Complete case analysis (School: Level 2) & $328(17)$ & .136 & .151 & $\begin{array}{l}-.160 \\
.433\end{array}$ & .37 & 0.13 \\
\hline $\begin{array}{l}\text { Analysis with multiple imputation } \\
\text { (School: Level 2) }\end{array}$ & $396(20)$ & .152 & .153 & $\begin{array}{l}-.148 \\
.452\end{array}$ & .32 & \\
\hline \multicolumn{7}{|c|}{ Model of exhaled breath CO levels in students (ppm) at post-test t2 } \\
\hline Model & $\mathrm{n}(\mathrm{N})$ & $\beta$ & SE & $95 \% \mathrm{Cl}$ & $\begin{array}{l}\mathrm{P} \\
\text { value }\end{array}$ & $\begin{array}{l}\text { Effect Size } \\
\text { (interention } \\
\text { compared to } \\
\text { treatment as } \\
\text { usual) } \\
\text { usual) }\end{array}$ \\
\hline Complete case analysis (School: Level 2) & $289(17)$ & -367 & .164 & $\begin{array}{l}-.688,- \\
.047\end{array}$ & $.03 *$ & -0.37 \\
\hline $\begin{array}{l}\text { Analysis with multiple imputation } \\
\text { (School: Level 2) }\end{array}$ & $396(20)$ & -377 & .187 & $\begin{array}{l}-.749,- \\
.005 \\
\end{array}$ & $.05^{*}$ & \\
\hline
\end{tabular}

*Significant at $p<0.05$

There was no significant effect of the intervention on the $\mathrm{CO}$ levels of the students at post-test $\mathrm{t} 1(\mathrm{p}=.37, \mathrm{ES}=.13)$. However, the intervention group had a significantly lower reading of carbon monoxide at the second post-test in comparison with the treatment as usual group ( $p<.03, E S=-.37$ ). This equated to 3 less smokers in the intervention arm. In fact, no students showed evidence of starting to smoke in the intervention arm, whilst 3 showed evidence of having commenced smoking in the treatment as usual arm. It was not possible to explore data further with a more fine grained model that looked at issues such as school type, sex or socio-economic factors as potential moderators of the effect because of limitations of sample size. However, further analysis was undertaken to explore the effects of missing data. Multiple imputation was used to explore the effects of missing data on models using clustering at the school level. It should be noted that there was low risk of cross contamination as three sites contained both treatment as usual and intervention classes. With multiple imputation at school level for missing data, the models still indicated significant effects of the programme in reduced $\mathrm{CO}$ levels at $\mathrm{t} 2(\mathrm{P}<0.05)$. If we look at only students who provided both a pre-test and post-test $\mathrm{t} 2$ sample we find significant differences in the means of intervention (2.59 ppm CO) and control (1.97 ppm CO) at pre-test $(F(1,205)=8.82, p<0.01)$. This is why it was important to control for pre-test differences in the models used. However, these differences were caused by small environmental background differences in the levels of $\mathrm{CO}$ in the exhaled breath of participants, as 
students with $\mathrm{CO}$ equal or less that 9ppm are not considered to be smokers (Deveci et al., 2004; Kendrick, 2015).

\section{Implementation and Fidelity}

Overall the programme was delivered with high fidelity. Of the 10 classrooms delivering the intervention, seven completed and returned the Programme Fidelity Proforma supplied by the research team. All responding teachers from intervention classrooms completed all four programme lessons. However, due to time constraints 3 teachers reported that they managed to complete only one of four possible extension activities in their classrooms. The mean time spent on class preparation was 17 minutes and the mean class length was 41 minutes, meaning that the mean intervention time was 246 minutes per student. This exceeded the planned implementation 'dose' and was indicative of the use of extension activities.

The overwhelming majority of pupils from all of the groups, when asked what they had learned from the programme, enthusiastically made reference to an increased knowledge on the awareness of the influences of the media and tobacco industry. The pupils spontaneously linked learning outcomes from the programme with concepts relating to gaining more knowledge about what influences their thoughts on smoking and the power of this, as well as the concept of addiction and the cost of smoking. Pupils particularly liked the DVD content and identified with the Northern Irish adolescents featured in the vignettes. Teachers engaged with the programme materials enthusiastically, and appreciated their alignment with curriculum.

\section{Discussion}

We have demonstrated that in high school settings the Deal Cool intervention delivers a significant positive short term effect (over an academic year) on preventing smoking initiation in Grade 8 pupils, equivalent to 1.5 fewer pupils taking up smoking per 100 pupils exposed to the intervention. Peers are reported to have the greatest impact on smoking behaviours (compared to parents), and this could amplify clustering effects in the data (Vitória, Salgueiro, Silva, \& de Vries, 2011) since Dead Cool is delivered at the class level. That means that the 'significant peers' from the students' own classes are also exposed to the intervention. The intervention was designed to affect student attitudes towards smoking (on which we have data) but mediation analysis will be reported in a further paper). Peers are previously reported to be important in initiating smoking behaviours in school-aged students (Campbell et al., 2008). Engaging in cooperative learning may place these peer interactions at the heart of any prevention process and allow students to: understand their own thinking, unpack what they think about smoking and why they think that, and this should lead to development of student metacognitive understandings on the topic. This should also help students understand 
their affective approach towards smoking. This type of pedagogy would thus support: cognitive aspects of thinking i.e. why would I smoke/not smoke (taking into account issues of health, cost, media manipulation); affective aspects, such as how do I feel about smoking, how do I feel about my health and how do I feel about media and advertisement manipulation of me and my generation; and the metacognitive, i.e. how do I know what I know, am I secure in my knowledge and understanding? Use of cooperative learning has been reported to promote metacognition during learning (Campione, Shapiro \& Brown, 1995). In addition, the cooperative learning activities that involved role-play allowed students to recognize their behaviours, shifting responsibility to them for the self-regulation of their own behaviour. These are reported to be essential components for the development of self-regulation and metacognition. In turn self-regulation and self-actualization are essential for transfer of planned behaviours to lived/actual behaviour (Simons, 1994). This has been previously reported in academic contexts of learning in primary/high schools (Thurston, Topping, Tolmie, Christie, Karagiannidou \& Murray 2009), and this study indicates similar processes may be active in successful smoking prevention programmes. In a recent systematic review of school based smoking prevention interventions, only those with social competence and or social influence components were effective, and overall tobacco prevention programmes showed no effect. However, what was apparent from the studies included in this systematic review is that few, if any, of the studies had actually taken account of what an effective pedagogy for the delivery would look like (Thomas et al., 2013; Thomas et al.,, 2015). Therefore, one of the most important findings from this study, is that we recommended that considerable thought be given to choosing the most appropriate pedagogy by public health professionals when planning interventions in schools. Without an effective pedagogy, any intervention will be limited in its impact and scope to facilitate change. It would appear that cooperative learning, with excellent evidence that it works in traditional school subjects such as mathematics and reading (Johnson et al., 2010), might be effective in smoking prevention also.

If the short-term benefits persisted over time, the potential health and financial benefits of Dead Cool could be modelled. Dead Cool prevented smoking uptake by any pupils in the intervention group. Scaled to every school, this would result in about 3.5 fewer deaths per 100 population due to smoking related disease (assuming smoking initiation, could be stopped due to Dead Cool) (Department of Health, Social Services and Public Safety Northern Ireland, 2012). Even used in Grade 8 this could reduce smoking rates by about $1.5 \%$. However, the persistence of the changes beyond this point was not established. Further study is needed to follow up the study group and ascertain whether the accrued benefits are sustained over an extended time period. The potential application of this programme in other settings is being explored by the team. In low- and middle-income countries, where early smoking initiation is widespread and the influence of the Tobacco industry is growing (World Health 
Organisation, 2017), a culturally sensitive translation of this programme could have considerable impact.

In relation to programme delivery, it is notable that the Dead Cool programme was delivered with high fidelity, with all lessons being delivered in all of the intervention schools. This was seen as being the result of the clearly defined structure of the resources and the training and on-going support provided to the teachers in the school. The fact that teachers who completed the 'dose' diary for their classes in implementation classrooms exceeded the planned dose was indicative of two things. Firstly, it was indicative that teachers continued to use the resources once started and obviously stuck with the planned lesson sequence. It is also probably related to the fact that some form of smoking prevention education is a statutory requirement in the Northern Ireland curriculum (Education Authority, 2018). Findings indicate that this programme would be ready for a scaled effectiveness trial.

\section{Limitations}

A limitation to be considered is the representativeness of the sample and the generalizability of the results. It is not unusual for studies of this nature to attract participants who are self-selecting and motivated, who may seek out similar programmes to participate in. This can mean that the gap between treatment as usual and intervention group is narrowed. A rigorous experimental design was used which ensured that participants were randomly allocated to either the intervention or treatment as usual group. At baseline (pre-test) these two groups were equivalent in terms of demographic characteristics as well as pre-test measures of the outcomes. This balance between the two groups increases our confidence that the improvement in outcomes for the intervention participants at the end of the study is an unbiased reflection of the impact of the programme and that the risk of Type 1 error is very low. Nevertheless, missing data may have played a part in findings. It should be noted that, overall, CO levels dropped in both intervention and treatment as usual samples. To minimise burden on teachers and pupils, the students were tested during a class period while completing the survey. While students were reminded that readings from the Smokelyser were confidential, it was not always possible to ensure that this was the case. The most likely explanation for this is probably due to students opting out of taking a test that they might fail. To counteract this we would recommend that future testing takes place in a private place (despite the impractical nature of collecting such data in a school setting). However, we did undertake analysis of model with multiple imputation and significant effects of the intervention were still detected. There was no evidence that the dropout rates between the intervention and treatment as usual groups differed. However, significant classroom effects were detected and so Type 2 error can be ruled out. There are a couple of issues that could have affected our analysis. One relates to potential contamination where intervention and treatment as usual classes were drawn from the same school. This was counteracted by having a 
memorandum of understanding with the schools and providing limited resources and training such that materials were not available to classes (schools in the UK are very careful not to infringe copyright). The other issue with having treatment as usual and intervention classes in the same school would be the effect that this has on the ICC during HLM analysis. This could have influenced results and the intervention may be more effective in some schools settings than others. The current trial aimed to be an efficacy trial but the promising results merit a larger implementation trial.

\section{References}

Bedfont (2015). Pico+ ${ }^{\mathrm{T} M}$ Smokerlyzer ${ }^{\circledR}$ Operating manual. Retrieved from: www. bedfont.com/file.php?f=ZmlsZSMjNzE0 (27 ${ }^{\text {th }}$ November 2015).

Campbell, R., Starkey, F., Holliday, J., Audrey, S., Bloor, M., Parry-Langdon, N., \& Moore, L. (2008). An informal school-based peer-led intervention for smoking prevention in adolescence (ASSIST): a cluster randomised trial. The Lancet, 371(9624), 1595-1602.

Campione, J. C., Shapiro, A.M., \& Brown, A.L. (1995). Forms of transfer in a community of learners: Flexible learning and understanding. In A. McKeough, J. Lupart, \& A. Marini (Eds.), Teaching for transfer: Fostering generalization in learning (pp. 35-68). Mahwah, NJ: Lawrence Erlbaum.

Cancer Research UK (2014). Tobacco statistics by socio-economic group. Retrieved from: http://www.cancerresearchuk.org/health-professional/cancerstatistics/risk/tobacco\#heading-Four (11 October 2017)

Cancer Focus NI (2015). Dead Cool manual. Belfast, UK: Cancer Focus NI.

Chassin, L., Presson, C.C., Sherman, S.J., \& Edwards, D.A. (1990). The natural history of cigarette smoking: predicting young-adult smoking outcomes from adolescent smoking patterns. Health Psychology, 9(6), 701.

Department of Health, Social Services and Public Safety Northern Ireland. (DHSSPSNI) (2012) Young persons' behaviour \& attitudes survey 2010. Belfast, UK: DHSSPSNI.

Deveci, S. E., Deveci, F., Açik, Y., Ozan, A.T. (2004). The measurement of exhaled carbon monoxide in healthy smokers and non-smokers. Respiratory Medicine, 98(6): 551-556.

DiFranza, J. R., Savageau, J.A., Fletcher, K., O'Loughlin, J., Pbert, L., Ockene, J.K., \& Wellman, R. J. (2007). Symptoms of tobacco dependence after brief intermittent use: The development and assessment of nicotine dependence in youth-2 study. Archives of Pediatrics \& Adolescent Medicine, 161(7), 704-710.

Dunne, L., Thurston, A., Gildea, A., \& Lazenbatt, A. (2016). Protocol: a randomised controlled trial evaluation of Cancer Focus NI's 'Dead Cool' smoking prevention programme in post-primary schools, International Journal of Educational Research. 75, 24-30.

Early Intervention Foundation (2018). EIF Evidence Standards. Retrieved from: 
http://www.eif.org.uk/eif-evidence-standards/ (1 ${ }^{\text {st }}$ February 2018).

Education Authority (2018). Learning for life and work. Retrieved from: http://ccea.org.uk/sites/default/files/docs/curriculum/area_of_learning/learning_life_w ork/pers_dev/ks3_personaldev.pdf (accessed 28th September 2018).

Fuller, E. (2012). Smoking, drinking and drug use among young people in England in 2011. Retrieved from: www.hscic.gov.uk/catalogue/PUB11334/smok-drindrug-youn-peop-eng-2012-repo.pdf (15th December 2015)

Johnson, D.W., Johnson, R.T., \& Roseth, C. (2010). Cooperative learning in middle schools: interrelationship of relationships and achievement. Middle Grades Research Journal, 5(1), 1-18.

Johnson, D.W., Johnson, R.T. (2012). Restorative Justice in the Classroom: Necessary Roles of Cooperative Context, Constructive Conflict, and Civic Values. Negotiation and Conflict Management Research, 5, (1), 4-28.

Kendrick, A. (2015). Exhaled carbon monoxide devices in smoking cessation. Retrieved from: www.erscongress2010.org/uploads/Document/e1/WEB_CHEMIN_2567_119452366 4.pdf (26th November 2015)

Levy, D. T., Currie, L., \& Clancy, L. (2013). Tobacco control policy in the UK: blueprint for the rest of Europe? The European Journal of Public Health, 23(2), 201206.

Health and Social Care Information Centre (2015). Statistics on smoking England. Available at: www.hscic.gov.uk/catalogue/PUB14988/smok-eng-2014rep.pdf Accessed 26th November 2015.

Moore, G., Audrey, S., Barker, M., Bond, L., Bonnell, C., Hardeman, W., Moore, L, O'Cathain, A., Tinati, T., Wight, D, \& Baird, J., (2017) Process evaluations of complex interventions. Retrieved from: https://www.mrc.ac.uk/documents/pdf/mrcphsrn-process-evaluation-guidance-final/ (11 Oct 2017)

Office for National Statistics (2013). Chapter 1 - Smoking (General Lifestyle Survey Overview - a report on the 2011 General Lifestyle Survey). Edinburgh, UK: her Majesty's Stationery Office.

Simons, P. R. J. (1994). Teaching and testing for metacognitive strategies. In T. Husen \& T. Postlethwaite (Eds.), The international encyclopaedia of education (2nd ed., Vol. 7, pp. 3788-3792). Oxford: Elsevier/Pergamon.

Taioli, E., \& Wynder, E. L. (1991). Effect of the age at which smoking begins on frequency of smoking in adulthood. New England Journal of Medicine, 325(13), 968969.

Thomas, R. E., McLellan, J., \& Perera, R. (2013). School-based programmes for preventing smoking. Cochrane Database of Systematic Reviews 2013, Issue 4. Art. No.: CD001293. DOI: 10.1002/14651858.CD001293.pub3.

Thomas, R. E., McLellan, J., \& Perera, R. (2015). Effectiveness of schoolbased smoking prevention curricula: systematic review and meta-analysis. British Medical Journal Open, 5:e006976. doi: 10.1136/bmjopen-2014-006976 
Tolmie, A.K., Topping, K.J., Christie, D., Donaldson, C., Howe, C.J., Jessiman, E., Livingston, K. \& Thurston, A. (2010). Social effects of collaborative learning in primary schools, Learning \& Instruction, 20(3), 177-191.

Thurston, A., Topping, K.J., Tolmie, A., Christie, D., Karagiannidou, \& Murray, P. (2009). Cooperative learning in science: Follow up from primary to high school. International Journal of Science Education, 32(4), 501-522.

Thurston, A., Dunne, L., Kee, F., Gildea, A., Craig, P., \& Stark, P. (2017). Evaluation of cancer focus Northern Ireland's 'Dead Cool' smoking prevention programme in Northern Ireland post-primary schools. Available from: http://www.isrctn.com/ISRCTN29351200 (7 June 2017).

Vitória, P. D., Salgueiro, M.F., Silva, S.A., \& de Vries, H. (2011), Social influence, intention to smoke, and adolescent smoking behaviour longitudinal relations. British Journal of Health Psychology, 16, 779-798.

World Health Organization (2006). Tobacco: deadly in any form or disguise. Geneva, Switzerland: World Health Organization.

World Health Organization (2017) Global Adult Tobacco Survey. Retrieved from: www.who.int/tobacco/surveillance/survey/gats/en/ (24 July 2017). 
Figure 1: Dead Cool Logic Model

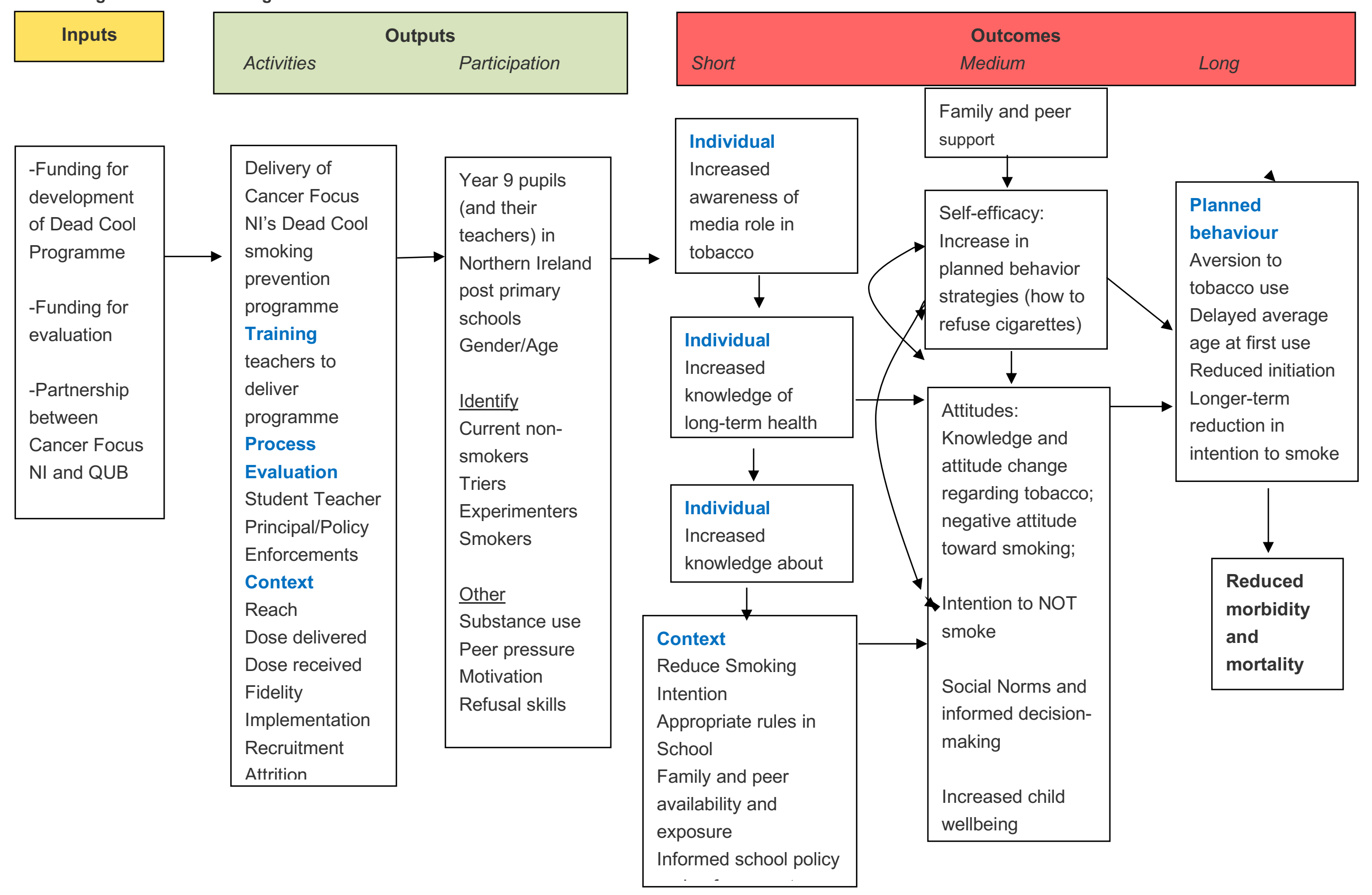

